\title{
In memoriam: Professor Lothar Bernd Zimmerhackl 1952-2010
}

\author{
Burkhard Tönshoff
}

Published online: 8 December 2010

(C) IPNA 2010

The international and particularly the German community of pediatricians and pediatric nephrologists are mourning, because it has lost an eminent colleague, scientist, and clinician, Lothar Bernd Zimmerhackl, who died suddenly on August 27, 2010. He was born on December 30, 1952 in Weinheim, Germany, where he also passed his Abitur (final secondary school examinations) in 1971. During his entire life, he kept well in touch with his beloved home region, the "Kurpfalz" (Electoral Palatinate). After his military service, he joined the University of Heidelberg in 1972, where he first studied mathematics, physics and chemistry with the intention of becoming a teacher. In 1976, he started to study medicine, first at the Free University Berlin, then from 1977 to 1982 again at the University of Heidelberg, where he graduated with his MD in 1982. In 1978, he joined as a research fellow the laboratory of Prof. Dr. Dr. s.c. Michael Steinhausen, a renowned renal physiologist and expert in glomerular microcirculation. In this laboratory, he was introduced to basic research and developed his approach to science, the precision of which followed him throughout his academic career. In this laboratory, he also successfully completed his doctoral thesis in physiology. He continued this work as a research associate until December 1982, when he joined the group of Professor Rex L. Jamison (Division of Nephrology, Department of Medicine) and Professor Channing R. Robertson (Department of Chemical Engineering) at Leland Stanford University in California, USA with a postdoctoral fellowship research grant from the German Research Foundation (DFG).

\footnotetext{
B. Tönshoff $(\bowtie)$

Department of Pediatrics I (General Pediatrics, Metabolism, Gastroenterology, Nephrology), University Children's Hospital, Im Neuenheimer Feld 430,

69120 Heidelberg, Germany

e-mail: Burkhard.Toenshoff@med.uni-heidelberg.de
}

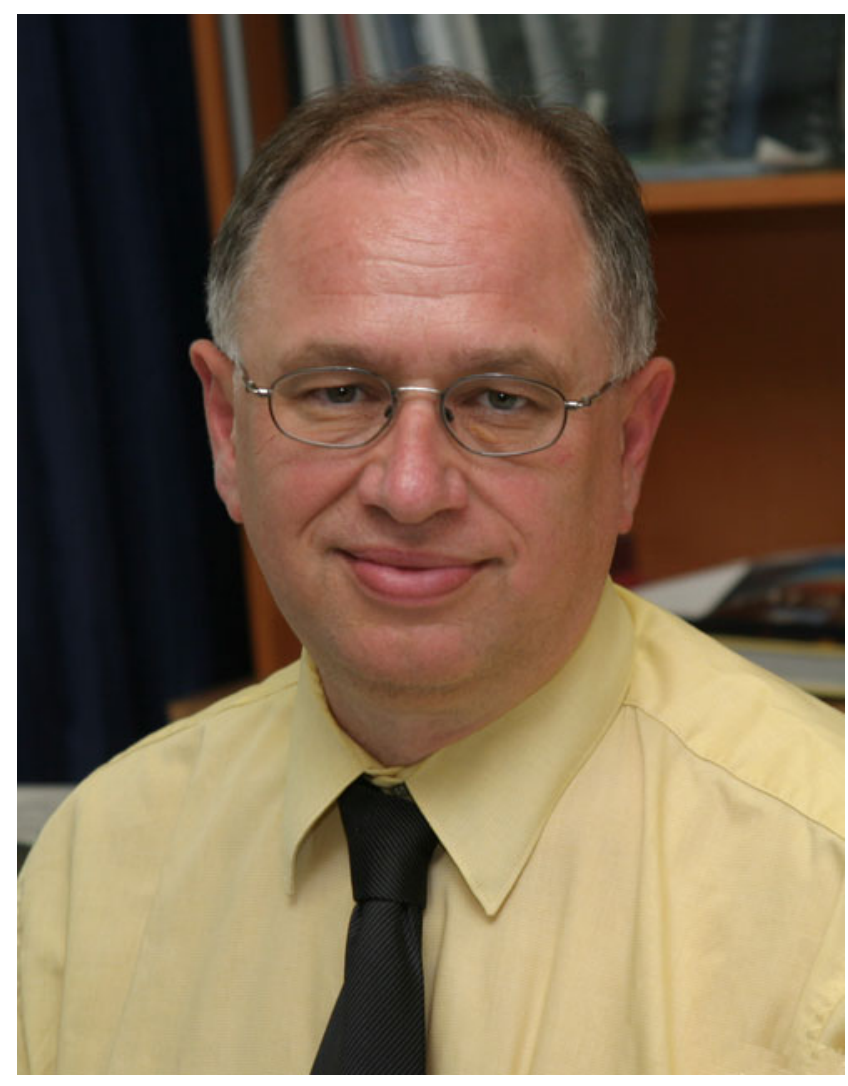

After this basic research fellowship in renal physiology, Bernd returned to Germany for his training in pediatrics and pediatric nephrology at the University Children's Hospital in Marburg from 1984 to 1988 under the direction of Professor Matthias Brandis. In 1988, he moved with Professor Brandis to the University Children's Hospital in Freiburg, where he obtained his license to practice pediatrics in 1980 and presented his habilitation thesis on the topic "Novel methods for the early detection of regional 
tubular disorders in childhood". Due to his academic achievements and his broad clinical experience and commitment, he quickly advanced to the position of a senior lecturer in Pediatrics and Vice Chairman of Pediatrics in Freiburg. In the year 2002 Bernd was appointed Professor and Chairman of the Department of Pediatrics at the Leopold-Franzens University in Innsbruck, Austria, a position he held until his death.

During his years in Freiburg and in Innsbruck, Bernd made continuous outstanding contributions to the field of pediatric nephrology. He was Secretary-Treasurer of the German Society of Pediatric Nephrology (GPN) (20002010) and played an active and important part in the life of this society. His research interests in the last 15 years focused on the pathophysiology and treatment of typical and atypical hemolytic uremic syndrome (HUS) and other complement-mediated diseases such as lupus erythematodes and more recently membranoproliferative glomerulonephritis (MPGN). He inaugurated and directed several national and international initiatives in this field, for example the European Paediatric Study Group for HUS. A scientific highlight since the year 2009 was the interdisciplinary International Symposium on HUS, MPGN and paroxysmal nocturnal hemoglobinuria in Innsbruck under his guidance. In the field of pediatric renal transplantation, he co-founded in 1996 the German Working Group on Paediatic Renal Transplantation, which for the first time in Germany initiated various multicenter prospective studies in this field. He also established the renowned annual workshop of this Working Group in the idyllic Black Forest village Hinterzarten in 1996; many of us enjoyed there the both professional and amicable atmosphere. Together with Therese Jungraithmayr, he initiated the European Collaborative FSGS Transplantation Study (ECoFTS). As a council member of the International Pediatric Transplant Association (IPTA), he organized the unforgettable 2005 World Congress of this society in Innsbruck. All this research was published in more than 250 articles in main-line journals or textbooks devoted to pediatrics, nephrology and transplantation.

Besides his interests in pediatric nephrology and pediatric transplantation, Bernd always stayed affiliated with the field of general pediatrics. He served in the council of the Austrian Society of Pediatrics (ÖGKJ), was representative of the ÖGKJ for medicines in children in UNEPSA (Union of National European Paediatric Societies and Associations), member of the EMEA Subgroup MEDICHILDREN and worked in the advisory board of the German Cancer Foundation. Among many other international activities, he was a member of the editorial board of five journals and contributed as a Section Editor Transplantation to our journal, Pediatric Nephrology.

Despite these multiple international obligations, one of Bernd's major commitments was the encouragement and support of young investigators and clinicians in pediatrics and pediatric nephrology. In his department in Innsbruck, he surrounded himself with a team of enthusiastic young investigators who quickly made original contributions in their specific fields of research. He was an outstanding teacher and mentor, devoted to training the next generation of clinicians and scientists. With his tremendous energy and his unpretentious and direct attitude, he guided his residents and fellows in their scientific and humanitarian approach towards the sick child. Abroad, he was respected and appreciated by his peers for his scientific curiosity, his enthusiasm, and his manifold accomplishments. He was never satisfied with previous achievements, but wanted to move the field forward with further research and innovation. He was a tireless worker, who sometimes took too less care of himself. We will commemorate him with great gratitude. His professional acumen, his wisdom, and cordial friendship will be greatly missed. 